\title{
Acoustic Characteristics of Recorded-Voice Depending on Gender in the External Ear Canal
}

\author{
Hui-Ra Kang ${ }^{a}$, Seung-Deok Heo ${ }^{b}$ \\ ${ }^{a}$ Department of Rehabilitation Science, Graduate School of Daegu University, Gyeongsan, Korea \\ ${ }^{b}$ Department of Speech-Language Pathology, College of Rehabilitation Science, Daegu University, Gyeongsan, Korea
}

\author{
Correspondence: Seung-Deok Heo, PhD \\ Department of Speech-Language Pathology, \\ College of Rehabilitation Science, Daegu \\ University, 201 Daegudae-ro, Jillyang-eup, \\ Gyeongsan 38453, Korea \\ Tel: $+82-53-850-4326$ \\ Fax: +82-53-850-4329 \\ E-mail: audiolog@daegu.ac.kr
}

Received: August 30, 2018

Revised: July 18, 2019

Accepted: August 20, 2019

This work is based on the master's thesis of the first author.

The authors acknowledge the skillful technical assistance of Dr. GiRyon Kim and Mr. GwangNyeon Kim at PhysioLab.
Objectives: The acoustic feature of vowels become different when they pass through the vocal tract, and also differ depending on gender differences such as anatomical structures and vocalization habits. Sound is perceived by the hearing organs through the outer ears, and the characteristics of sound also become different by passing the outer ears, which act as resonators, just as the vocal tracts do. Thus, this study aims to analyze the formant frequency of the $/ \mathrm{a} /, / \mathrm{i} /, / \mathrm{l} /, / \mathrm{e} /, / \mathrm{o} /$ recorded in the external auditory canal (EAC) and to investigate gender differences. Methods: Ten female (mean age, $23 \pm 3.77$ years) and 8 male (mean age, $25 \pm 3.68$ years) participated as speakers, and 1 male participated as a listener. Two condenser microphones connected with a probe tube were used for sound recording. Male and female voices were recorded, which were fixed probe tube at upper pinna and in the EAC. After determining the F1, F2, F3, and F4, formant frequencies were analyzed through descriptive statistics. Gender differences between upper pinna and EAC were examined and analyzed using an independent sample $t$-test. Results: In terms of gender differences in the upper pinna, female voices in F1, F2, F3, and F4 ( $p=.000)$ of $/ \mathrm{a} /, \mathrm{F} 1 \quad(p=.000), \mathrm{F} 3(p=$ $.016)$, and F4 ( $p=.000)$ of $/ \mathrm{i} /$, F1 $(p=.000)$ of $/ \mathrm{u} /, \mathrm{F} 1(p=.000), \mathrm{F} 3(p=.000)$, and F4 $(p=.000)$ of /e/, and F1 ( $p=.015), \mathrm{F} 4(p=.000)$ of /o/ were significantly higher than male voices. However, $\mathrm{F} 2(p=.013)$ of $/ \mathrm{u} /, \mathrm{F} 2(p=.000)$ and F3 $(p=.000)$ of /o/ were significantly lower. On the other hand, in the EAC, F1, F2, F3, and F4 ( $p=.000)$ of $/ \mathrm{a} /, \mathrm{F} 1(p=.005), \mathrm{F} 2(p=.041), \mathrm{F} 3(p=$ $.023)$, and F4 ( $p=.000)$ of /i/, F2, F3, and F4 ( $p=.000)$ of /e/ were significantly higher for female participants. Conclusion: With respect to the gender difference of voice in the upper pinna, the female vowel space was observed to be spacious on the whole, affected by the F1 and F2, F3 and F4 of rounded and unrounded vowel. In case of the voice in the ear canal, the difference between low and high vowels and the difference between F1 and F2 of the front and the back vowels of the female participants became larger. F3 was higher in rounded and unrounded vowels of female participants. F4 was higher in low, high, front and the back vowels of female participants. In the ear canal, the vowel space of both genders showed conspicuous differences, and notably the vowel space of F3 and F4 was observed independently without any overlapping.

Keywords: Pinna, External auditory canal, Formant frequency, Gender effect, Voice analysis
모음은 성대를 일정한 속도로 진동하여 만든 음원으로 조음기 관을 움직여 성도를 변형시켜 발성하게 된다. 모음마다 음향학적 특성이 달라지는 것은 이와 관련된다. 모음의 음향학적 특성은 기 본주파수, 배음 또는 화음, 강도 등으로 표현할 수 있다(Ferrand, 2007; Martin \& Clark, 2016). 성도는 한쪽이 성문으로 닫히고 반대
쪽이 열린 공명관으로, 구강, 비강, 인두강, 입술강 등이 포함된다. 성도는 성대 음성의 특정한 배음을 강조하거나 억제하여 배음 구 성을 변화시킨다(Kent \& Read, 2002). 이 배음들은 포먼트 주파수 라 하며, 음성의 경우 $5,000 \mathrm{~Hz}$ 이하 주파수 범위에서의 봉우리 (peak)들을 관찰하고 차례로 $\mathrm{F}_{1}, \mathrm{~F}_{2}, \mathrm{~F}_{3}, \mathrm{~F}_{4}, \cdots \mathrm{F}_{\mathrm{n}}$ 등으로 표시한다 
(Borden, Harris, \& Raphael, 2000; Ferrand, 2007; Martin \& Clark, 2016).

음향학적 연구에서 음성은 입술 밖 바로 앞에서 녹음하고, 입술 밖 음성의 음향학적 특성은 성별에 따라 다르다. 그러나 사람은 청 각기관인 외이를 통해 소리를 듣기 때문에 성도와 마찬가지로 공명 기인 외이의 영향으로 음향 증폭(공명 이득)이 생기며, 이에 영향을 받을 수 있다. 공명 이득은 머리나 몸통의 간섭에 의해서도 생긴다. 외이에서 공명 이득은 이개가 $4,000 \mathrm{~Hz}$ 범위를 $3 \mathrm{~dB}$ 정도, 이개강 이 5,000-6,000 Hz 대역에서 $10 \mathrm{~dB}$ 정도, 외이도가 $2,500-2,700 \mathrm{~Hz}$ 범위에서 $13 \mathrm{~dB}$ 정도이다(Heo, 2012; Heo \& Yoo, 2002; Heo, Choi, \& Kang, 2006; Heo, Lee, Jeon, \& Kim, 2010). 서로 다른 주파수에 서 발생하는 공명 이득은 포먼트 주파수를 포함한 다양한 음향 특 성에도 영향을 줄 수 있으며, 남녀 음성에서도 당연히 서로 다른 차 이가 있을 수 있다. 실제로 외이도 내부 음성은 음원으로부터 거리 및 외이 공명 등의 영향으로 달라질 수 있으며, 남자 및 여자 화자 음성 각각을 따로 분석한 연구가 있다(Heo, Kang, \& Ko, 2017; Heo \& Kang, 2017; Heo \& Kim, 2018; Heo, Kang, \& Kim, 2018). 그러나 이들 연구는 남자 또는 여자를 대상으로, 서로 다른 녹음 조건에서 서로 음향 특성을 분석한 연구이며, 같은 조건에서 성별 차이에 따 른 음향 특성을 분석하지는 않았다.

성별에 따른 이개 상부 음성의 음향학적 특성은 해부학적 및 행 동학적 측면에서 차이를 보인다(Simpson, 2002, 2009; Whiteside, 2001). 해부학적으로는 성대 두께 및 성도 길이 차이에 의한 기능적 변화가 생기는 것을 말한다. 일반적으로 성대 두께는 여자보다 남 자가 더 크고 두꺼워서 남자의 기본주파수와 포먼트 주파수가 더 낮고(Oh, 2012; Seong, 2005; Yang, 1998b), 성도 길이는 여자가 남 자보다 짧아서 여자의 포먼트 주파수가 높다(Oh, 2012; Simpson, 2009; Yoo, Kim, Suh, \& Kim, 2017). 행동학적으로는 여자의 포먼 트 주파수가 발화 명료도를 높이기 위해 모음 공간을 더 넓게 사용 하면서 높아진다(Oh, 2012; Diehl, Lindblom, Hoemeke, \& Fahey, 1996). 음성 강도는 거리가 멀어지면서 낮아지는데, 특히 에너지 강 도가 낮은 고음역에서 감쇄는 말소리 명료도를 낮아지게 할 수 있 고, 감정 정보의 소실이 생길 수 있다. 이에 비해 외이의 공명 이득 은 고음역에 집중되어 있어서 음장에서의 감쇄를 보상하는 것으로 추정된다. 그러나 이들 연구는 외이 공명과 간섭 등의 영향을 포함 하지 않았다. 따라서 같은 조건으로 외이도에서 남녀 음성을 녹음 하여 포먼트 주파수차이를 비교할 필요가 있다.

이 연구는 공명기인 외이의 간섭을 받은 남녀 음성을 외이도에서 녹음한 후음향학적 특성을 비교하는 데 목적이 있다.

\section{연구방법}

\section{연구대상}

연구에는 10 명의 여자(23세 \pm 3.77$)$ 와 8 명의 남자 $(25$ 세 \pm 3.68$)$ 가 발화자로 참여하였고, 이들이 발화한 음성은 또 다른 23 세의 남 자 1 명(청자)의 외이도에서 녹음하였다.

발화자는 귀와 두경부의 기형이나 외상 병력이 없었고, 청력, 발 성, 공명, 조음 등이 모두 정상이었다. 이들의 음성은 청지각적 평가 및 음향학적 특성인 음도, 강도, 음질, 그리고 모음정확도와 구어 명료도 등이 모두 정상 범위에서 관찰되었다. 청자는 광원이 있는 비디오 이경(XVS3; Chammed, Gunpo, Korea)으로 신체검사를 받 았고, 신체검사상 외이도와 고막 등은 이상이 관찰되지 않았다. 고 막 및 중이 상태는 중이 이미턴스검사기(GSI 33 middle ear analyzer; Grason-Stadler Inc., Eden Prairie, MN, USA)를 이용하였고, 검 사 결과인 고막운동도에서는 외이도 용적, 중이강 압력, 정적 탄성 등이 모두 정상 범위에서 관찰되었다.

\section{연구방법}

실험 모음은 이중모음 성격이 없고, 사용빈도가 높은 평순 중설 저모음///, 평순 전설 고모음///, 원순 후설 고모음/T// 평순 전설 중모음/ / / / 원순 후설 중모음/ㄴ/ 등의 5 개로 하였다. 발성과 녹음 은 방음실(IAC Series 1204A)에서 시행하였고, 발화자는 청자의 왼쪽 $45^{\circ}$ 방향, $50 \mathrm{~cm}$ 이내에서 서서 발화하였다. 발화자는 언어병 리전문가에게 별도의 발성 교육을 받고, 충분한 연습을 한 후 5 초 정도씩 2회 발성하였다.

음성 녹음용 마이크는 주파수 범위가 $20-16,000 \mathrm{~Hz}$, 민감도가 $-39 \pm 2 \mathrm{~dB} @ 94 \mathrm{~dB}$ SPL인 두 개의 콘덴서 마이크(PMOF-9745P39UQ; Mallory Sonalert Products Inc., Indianapolis, IN, USA)를 이용하였다. 두 개의 콘덴서 마이크는 일회용 $10 \mathrm{~mL}$ 주사기에 넣고 몰딩하였다. 주사기에 몰딩한 녹음용 콘덴서는 $5 \mathrm{~mm}$ 만 남기고 평 면 절단한 의료용 18 게이지 주사 바늘 $\left(18 \mathrm{G} \times 1 \frac{1 / 2}{2}\right)$ 과 연결하였고, 평면 절단한 바늘 끝에 직경 $0.6 \mathrm{~mm}$, 길이 $75 \mathrm{~mm}$ 의 실리콘 탐침관 (probe tube)을 연결하였다.

두 개의 마이크 중 하나는 탐침관 끝이 화자를 향하게 하여 이개 (pinna) 상부에 고정하였고, 다른 하나는 광원이 있는 비디오 이경 (XVS3)으로 감시하면서 탐침관 끝을 고막 $1 \mathrm{~cm}$ 가까이 외이도(external auditory canal) 내부로 넣은 후 이수(lobule)에 고정하였다.

녹음은 2채널 증폭기(Scarlett 6i6; Focusrite, High Wycombe, $\mathrm{UK}$ )로 증폭한 후, Adobe Audition CS6로 44,100 Hz, 양자화 $16 \mathrm{bit}$ 로 녹음하고 개인용 컴퓨터에 저장하였다. 두 개 마이크는 $100 \mathrm{~Hz}$ 
단위의 $100-8,000 \mathrm{~Hz}$ 사이의 순음을 이용하여 보정하였다.

녹음 음성은 Goldwave로 채널을 분리하였고, 분리한 각각의 음 성은 육안으로 안정된 구간을 선택한 후, Praat을 이용하여 포먼트 주파수를 F4까지 분석하였다.

분석 결과, 이개 상부와 외이도 내부에서 녹음한 남녀 음성의 F1, $\mathrm{F} 2, \mathrm{~F} 3, \mathrm{~F} 4$ 의 평균과 표준편차로 기술통계값을 제시하였고, 이개 상 부와 외이도 내부에서 남녀 음성의 차이는 독립표본 $t$-test로 검증 하였다(SPSS version 22.0).

마지막으로 이개 상부와 외이도 내부 음성 각각의 모음 사각도 를 그린 후, 이들 관계를 육안으로 비교하였다. 모음 사각도는 F1과 F2는 물론 외이 공명에 영향을 받은 주파수 대역이 포함된 F3와 F4 를 이용하여 그렸다.

\section{연구결과}

이개 상부에서 녹음한 음성 / / /,/ / /, / T/,/ / /,/ / / 의 여자와 남자 의 포먼트 주파수 F1, F2, F3, F4는 각각 Table 1과 같이 관찰되었다.

이개 상부에서 녹음한 남녀 음성 사이에는 / / / 의 F1, F2, F3, F4 $(p=.000), / / /$ 의 F1 ( $p=.000), \mathrm{F} 3(p=.012), \mathrm{F} 4(p=.000), / \mathrm{T} /$ 의 F1 $(p=.000), / / 1 /$ 의 F1 ( $p=.000), \mathrm{F} 2(p=.004), \mathrm{F} 3(p=.000), \mathrm{F} 4(p=$
.000), / 기의 F1 ( $p=.015)$ 에서 여자가 유의하게 높았고, /T/의 F2 ( $p=.039), /$ / $/$ 의 F2 ( $p=.004), \mathrm{F} 3, \mathrm{~F} 4$ ( $p=.000)$ 에서 남자가 유의하 게 높았다(Table 1, Figure 1).

외이도 내부에서 녹음한 음성 / / /, / / / / T/,/N/, / ㄱ/의 여자와 남자의 포먼트 주파수 F1, F2, F3, F4는 각각 Table 1과 같이 관찰되 었다.

외이도 내부 남녀 음성 사이에서는 / / / 의 F1, F2, F3, F4 ( $p=.000)$, / / 의 F1 ( $p=.005), \mathrm{F} 2$ ( $p=.041), \mathrm{F} 3$ ( $p=.023), \mathrm{F} 4$ ( $p=.000), / / 1 /$ 의 $\mathrm{F} 2(p=.001), \mathrm{F} 3, \mathrm{~F} 4$ ( $p=.000)$ 에서 여자가 유의하게 높았다(Table 1).

이개 상부에서 녹음한 남녀 음성의 F1과 F2 모음 사각도를 살펴 보면, 사각도 윤곽은 남자의 경우/L//, T/,//로 구성되는 오른쪽 면이 오목한 사각형으로 관찰된 데 반해 여자의 경우// / 가 왼쪽으 로 다소 돌출되는 사각형으로 관찰되었다. 공간 면적은 남자보다 여자가 넓게 관찰되었다(Figure 1A).

이개 상부에서 녹음한 남녀 음성의 F3와 F4 모음 사각도를 살펴 보면, 사각도 윤곽은 남자의 경우///와///가 꼭짓점을 이루는 부 메랑 모양으로 관찰되었고, 여자의 경우///, / T/,//n/로 구성된 면 이 다소 긴 변형 직사각형으로 관찰되었다. 공간 면적은 $\mathrm{F} 1, \mathrm{~F} 2$ 와 마찬가지로 여자가 넓게 관찰되었다(Figure 1B).

외이도에서 녹음한 남녀 음성의 F1, F2 모음 사각도를 살펴보면,

Table 1. Formant frequency of female and male participants in the upper pinna and the ear canal (unit: $\mathrm{Hz}$ )

\begin{tabular}{|c|c|c|c|c|c|c|c|c|c|}
\hline & \multirow{2}{*}{$\begin{array}{l}\text { Formant } \\
\text { frequency }\end{array}$} & \multicolumn{4}{|c|}{ Sound field (upper pinna) } & \multicolumn{4}{|c|}{ External ear canal } \\
\hline & & Female (A) & Male (B) & $A-B$ & $p$-value & Female (A) & Male (B) & $A-B$ & $p$-value \\
\hline \multirow[t]{4}{*}{ r } & $\mathrm{F} 1$ & $812.33(65.46)$ & $581.93(91.58)$ & 230.40 & .000 & $949.24(74.97)$ & $697.22(48.45)$ & 252.02 & .000 \\
\hline & F2 & 1,345.77 (86.27) & $1,063.88(47.10)$ & 281.36 & .000 & $2,491.18(240.25)$ & $1,170.42$ (93.66) & $1,320.76$ & .000 \\
\hline & F3 & $3,268.24$ (132.03) & $2,869.60(74.49)$ & 389.64 & .000 & $3,210.16$ (168.04 & 2,865.18 (157.58) & 344.98 & .000 \\
\hline & F4 & $4,400.20(109.29)$ & 3,789.65 (237.94) & 610.55 & .000 & 4,277.25 (197.53) & 3,735.83 (225.94) & 514.42 & .000 \\
\hline \multirow[t]{4}{*}{ I } & $\mathrm{F} 1$ & 438.14 (20.97) & 282.38 (32.77) & 155.76 & .000 & 343.42 (32.22) & 289.31 (39.24) & 54.11 & .005 \\
\hline & F2 & 2,266.87 (316.15) & 2,070.91 (207.61) & 195.96 & .134 & $2,405.76$ (455.18) & 2,021.23 (193.93) & 384.53 & .041 \\
\hline & F3 & $3,133.64$ (180.24) & 2,940.94 (99.41) & 192.70 & .012 & 3,120.84 (249.03) & 2,871.66 (138.76) & 249.18 & .023 \\
\hline & F4 & 4,131.07 (251.12) & $3,614.55$ (150.59) & 516.52 & .000 & $3,914.46$ (200.54) & $3,496.35(153.76)$ & 418.11 & .000 \\
\hline \multirow[t]{4}{*}{$\top$} & $\mathrm{F} 1$ & 453.22 (23.50) & 316.53 (21.50) & 136.69 & .000 & 432.89 (39.41) & 378.30 (89.60) & 54.59 & .143 \\
\hline & F2 & 922.88 (90.85) & $1,373.80(501.74)$ & -450.92 & .039 & 1,533.21 (267.16) & 1,482.63 (583.50) & 50.58 & .825 \\
\hline & F3 & $2,567.38(156.39)$ & $2,722.53(279.19)$ & -155.15 & .189 & $2,896.41$ (107.90) & 2,738.96 (515.10) & 157.45 & .422 \\
\hline & F4 & 3,683.07 (183.36) & $3,761.68(197.20)$ & -78.61 & .395 & $3,976.72(198.20)$ & $3,679.25(432.11)$ & 297.47 & .104 \\
\hline \multirow[t]{4}{*}{ H } & $\mathrm{F} 1$ & 648.03 (62.85) & 473.65 (42.34) & 174.38 & .000 & 520.63 (88.30) & $499.10(35.45)$ & 21.53 & .495 \\
\hline & F2 & 2,231.26 (139.75) & $2,009.35$ (136.07) & 221.91 & .004 & 2,330.61 (79.64) & $1,856.76(270.54)$ & 473.85 & .001 \\
\hline & F3 & $3,197.78(215.95)$ & $2,766.18(158.52)$ & 431.60 & .000 & $3,067.91(148.40)$ & $2,609.10(121.54)$ & 458.81 & .000 \\
\hline & F4 & 4,333.19 (195.22) & 3,772.86 (221.52) & 561.33 & .000 & $3,976.58(241.74)$ & $3,534.15(145.41)$ & 442.43 & .000 \\
\hline \multirow[t]{4}{*}{$\perp$} & $\mathrm{F} 1$ & 460.65 (28.55) & 420.35 (34.19) & 40.30 & .015 & $465.77(27.12)$ & 455.88 (22.52) & 9.89 & .420 \\
\hline & F2 & 817.22 (25.89) & 1,627.92 (533.52) & -810.70 & .004 & $1,582.45(647.54)$ & 1,593.17 (741.34) & -10.72 & .974 \\
\hline & F3 & $2,651.64$ (195.49) & $3,026.34$ (178.21) & -374.70 & .000 & 3,090.12 (208.06) & 2,814.16 (515.41) & 275.96 & .189 \\
\hline & F4 & $3,638.88$ (228.79) & 4,088.39 (201.51) & -449.51 & .000 & $3,945.46$ (299.84) & $3,844.67$ (464.04) & 100.79 & .584 \\
\hline
\end{tabular}


F1 frequency

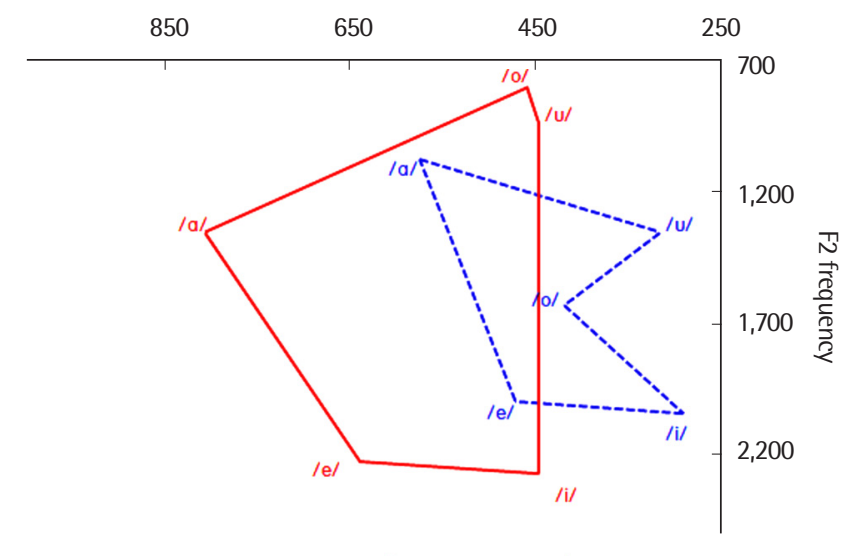

Female $\longrightarrow$ Male -----

(A)

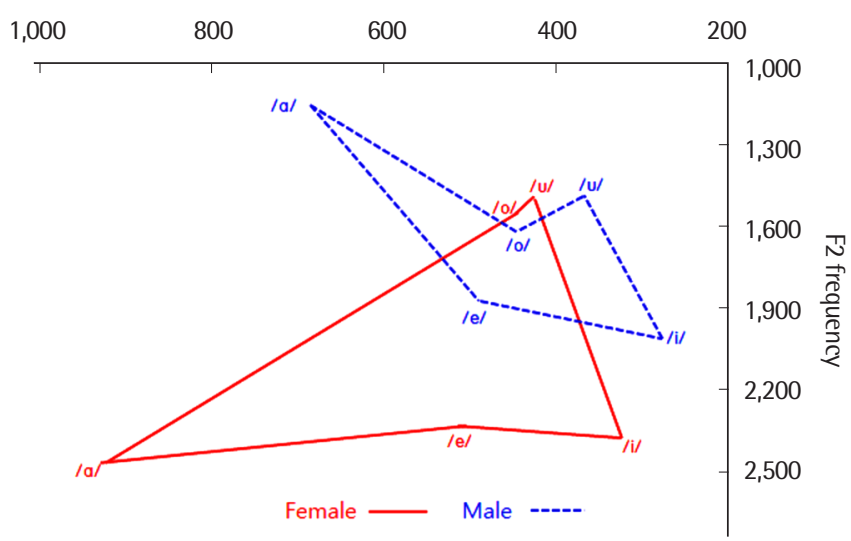

(C)
F3 frequency

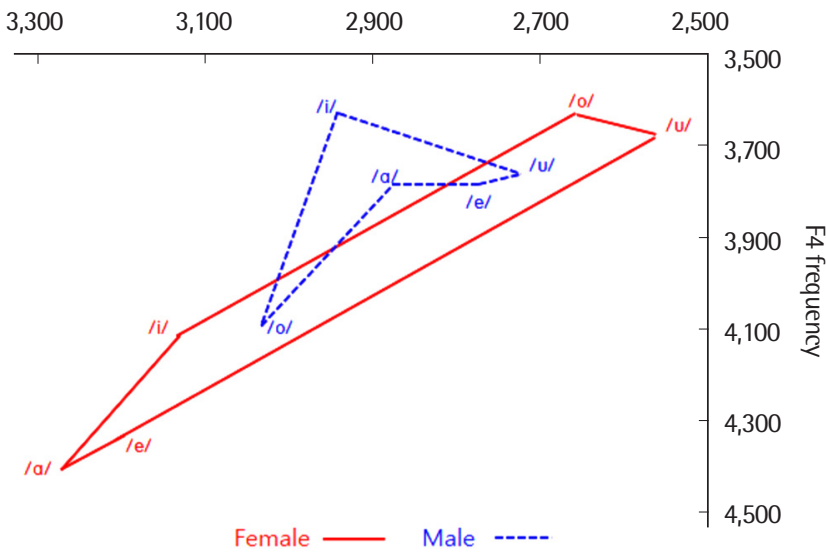

(B)

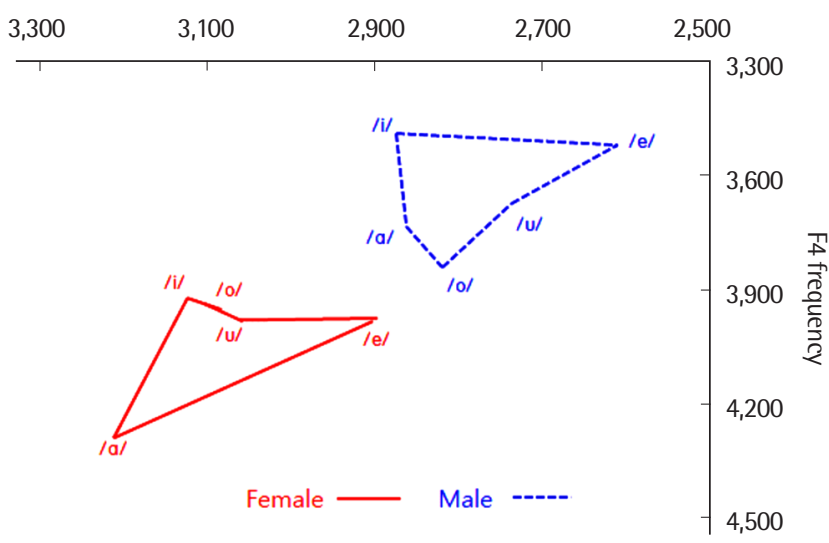

(D)

Figure 1. Formant frequency change of voice in the upper pinna and the ear canal. (A) The F1 and F2 and (B) the F3 and F4 of the voice of both genders in the upper pinna. (C) The F1 and F2 and (D) the F3 and F4 of that of both genders in the ear canal.

사각도 윤곽은 남자의 경우/F/가 왼쪽 위로 꼭짓점을 이루는 나팔 모양으로 관찰되었고, 여자에서// /,///,// / 가 밑면을 이루는 직각 삼각형으로 관찰되었다. 공간 면적은 여자가 넓게 관찰되었다(Figure 1C).

외이도에서 녹음한 남녀 음성의 F3, F4 모음 사각도를 살펴보면, 사각도 윤곽은 남녀 모두 삼각형 모양으로 관찰되었으나 남자의 경 우/L//, / T/,/ㄱ//가, 여자의 경우 / / / 와 / / / 가 밑변을 구성하였다. 공간 면적은 남녀 모두 비슷하게 관찰되었다. 그러나 음장에서 녹 음한 음성의 F1와 F2, F3와 F4 및 외이도에서 녹음한 음성의 F1과 F2의 모음 사각도들이 상당 부분 중복되었으나 외이도에서 녹음한 음성의 F3와 F4의 모음 사각도는 중복되지 않고 분리되어 관찰되 었다(Figure 1D).

\section{논의 및 결론}

이 연구는 이개 상부와 외이도 내부에서 녹음한 남녀 음성의 음 향학적 특성 차이를 알아보고자 하였다.

이개 상부에서 녹음한 음성의 전반적인 포먼트 주파수 변화는 $\mathrm{F} 1$ 의 경우 저모음, 고모음, 전설모음, 후설모음에서, $\mathrm{F} 2$ 의 경우 저모 음과 중설모음에서 여자가 모두 높게 관찰되었다. 그러나 F2의 경 우 후설모음에서 남자가 높게 관찰되었다. F3과 F4의 경우 저모음, 전설모음, 중설모음에서 여자가 높게 관찰되었다. 원순모음 / / / 의 $\mathrm{F} 3$ 과 F4의 경우 남자가 높게 관찰되었다.

개별 포먼트 주파수 변화에서 여자의 저모음 F1과 고모음 F2가 높아진 것은 조음 과정에서 턱을 내리고, 혀를 치경쪽으로 내밀어 생긴 변화이다. 이를 통해 저모음과 고모음, 전설모음과 후설모음 
의 차이를 크게 한다(Hwang, 2007; Hwang, Kim, Jeong, \& Lee, 2007; Koo, 2005; Oh, 2012; Yoon \& Kim, 2015).

F3은 입술을 돌출하고 둥글게 할수록 낮아지고(Kim, Kim, Kim, \& Jang, 2013; Seong, 2005; Ferrand, 2007; Yang, 2012; Borden, Harris, \& Raphael, 1994), 성도 길이가 짧아지거나(Kim et al., 2013) 발 화 강도가 강해지면(Kim, 2016) 높아진다. 이 연구에서 여자의 원 순모음 F3이 낮아진 것은 조음점인 입술을 강하게 협착하여 공명 을 낮게(Shin \& Yoon, 1987)하고, 이를 통해 원순모음을 분명하게 발성하는 데 도움을 준 것으로 볼 수 있다.

$\mathrm{F} 4$ 는 후두 및 후두실의 위치, 개인의 감정 인식(Hong, Kim, Jung, Yoon, \& Kim, 1998; Kim et al., 2013) 등과 관련이 있을 것으로 추 정한다. 특히 감정은 전설보다 후설모음에서, 포먼트가 균일하고 에너지가 높은//에서 변별력이 높다(Yi, 2011). 이 연구에서 이개 상부로부터 측정한 모음의 특성은 음원 가까이에서 측정한 연구들 과 비교하여 음원으로부터 거리가 연장되었음에도 불구하고 전반 적으로 선행연구 결과와 비슷한 특성을 보였다.

이개 상부 음성의 남녀 간 모음 공간 면적 차이는 모든 모음의 F1, $\mathrm{F} 2$, 원순모음 및 평순모음의 F3, F4 등의 변화에 영향으로 전체적으 로 여자가 넓게 활용하는 것으로 분석할 수 있다. 여자의 F1과 F2의 경우 해부학적 차이로 인하여 저모음과 전설모음일수록 차이가 커 져서 $(\mathrm{Oh}, 2012)$ 모음 공간 면적이 넓어진 것이다. 이것은 이개 상부 음성이 입술 바로 앞 음성과 마찬가지로 음장 공간에서 전파되기 때문에 그 특성을 유지하는 것으로 볼 수 있다. 그러나 F3과 F4는 음원으로부터 거리와 두개골의 간섭 등의 영향으로 공명 주파수가 크게 이동하여 공간 면적이 넓어진 것으로 해석할 수 있다.

외이도 내부 음성은 이개 상부 음성의 기본적 자질을 유지하면 서 외이도의 구조상 특성, 공간 부피의 감소, 매질 온도 변화 등에 영향을 받았다.

$\mathrm{F} 1$ 과 F2는 조음활동 과정에서 협착 등에 영향을 받아 높아지는 데(Cho, 2003; Oh, 2012; Simpson, 2002, 2009; Whiteside, 2001; Yang, 1998a), 저모음의 $\mathrm{F} 1$ 은 입구가 좁고 부피가 감소한 외이도 내 부로 들어오면서 높아졌고, 전설모음의 F2 또는 치경 협착과 좁아 진 외이도 입구를 지나면서 더욱 높아졌다. F3와 F4는 입술의 둥근 정도에 영향을 받아 원순모음일수록 낮아지고, 평순모음일수록 높 아지는데, 둥근 외이도 입구가 대부분 모음에 영향을 주어 높아졌 고, 음원으로부터 거리가 멀어지고, 외이도의 모양과 물리적 환경, 외이도 및 이개강의 공명 등에 간섭을 받아 전반적으로 높아졌다 (Heo \& Kang, 2017; Heo \& Kim, 2018; Heo et al., 2017; Heo et al., 2018).

외이도 내부 음성의 남녀 간 모음 공간 면적 차이를 살펴보면, F1,
$\mathrm{F} 2$ 는 여자의 저모음, 고모음과 전설모음 및 후설모음에서 차이가 커졌고. F3은 여자의 원순모음과 평순모음에서 높아졌다. 아울러 $\mathrm{F} 4$ 는 여자의 저모음, 고모음과 전설모음 및 후설모음에서 모두 높 아지면서 남녀 음성 사이의 차이가 크게 관찰되었다. 이것은 F1, F2 의 경우 모음 공간을 넓게 하여 변별력을 향상시키는데, 특히 전설 모음 F2의 경우 모음 강도가 낮고(Choi, Park, \& Seong, 2010; Kim, 2016), 음원으로부터 거리가 멀어지면서 에너지 손실이 많아진다. 그러나 협착 구간인 외이도는 대부분 모음의 F2 주파수 범위인 평 균 $2,639 \mathrm{~Hz}$ 에서 공명이 발생하고(Heo, 2012), 이 공명에 의해 평균 $18.1 \mathrm{~dB}$ 의 증폭 $(\mathrm{Heo}, 2012)$ 이 발생하여 모음의 에너지를 보상하는 것으로 보인다. F3의 경우 직경이 타원형인 관을 형성하는 외이도 가 평순모음을 원순화한 것으로 보인다. F3과 F4의 경우 음원과의 거리, 이개강과 외이도 공명, 외이도의 구조와 부피 및 매질 온도 등 물리적 환경 등 복합적인 간섭을 받은 것(Heo \& Kang, 2017; Heo \& Kim, 2018; Heo et al., 2017; Heo et al., 2018)으로 판단된다. 아울러 이개(pinna), 이개강(cavum concha), 외이도 등에서 발생하는 외이 공명은 F3, F4 공명 주파수를 이동시켜 음색(timbre)을 보상하고, $\mathrm{F} 3, \mathrm{~F} 4$ 진폭을 크게 하여 어음 변별을 개선하는 데 도움을 줄 것으 로 판단된다. 음색의 보상은 음장에서 혀의 고저 대립이 없는 음성 (Moon, 2007; Yang, 2008; Yoon \& Kim, 2015)의 인식이나 남녀 구 분이 모호해지는 원순모음의 변별력 향상에 도움을 주는 것으로 보인다. F4의 경우 감정 인식에 관여하는 데(Kim et al., 2013; Waaramaa, Laukkanen, Alku, \& Väyrynen, 2008; Yi, 2011), 외이도는 공 명 이득을 통해 감정 공감에 기여할 것으로 추정된다.

이상을 요약하면, 이개 상부 음성은 음원으로부터 거리가 멀어 지고, 두개골의 간섭을 받지만 입술 바로 앞에서 녹음한 음성의 음 향학적 특성을 유지하는 경향을 보였다. 이개 상부 음성의 남녀 간 차이는 모음 공간이 일부 겹쳐지지만 $\mathrm{F} 1, \mathrm{~F} 2$, 원순모음 및 평순모음 의 F3, F4 등에 영향을 받아 여자가 전체적으로 넓게 관찰되었다.

외이도 내부 음성은 외이도 물리적 환경 등에 영향을 받아 여자 음성이 더 높아지는 경향을 보였다. 외이도 내부 음성의 남녀 간 차 이는 여자의 저모음, 고모음과 전설모음 및 후설모음에서 F1과 F2 의 차이가 커졌다. F3은 여자의 원순모음과 평순모음에서 높아졌고, $\mathrm{F} 4$ 는 여자의 저모음, 고모음과 전설모음 및 후설모음에서 모두 높 아지면서 남녀 음성 사이의 차이가 크게 관찰되었다. 외이도 내부 음성의 남녀 간 모음 공간은 분명하게 구분되고, 특히 F3, F4의 모음 공간은 고저 대립이 없는 음성 및 원순모음 등이 중복되지 않고 따 로 독립되어 관찰되었다. 모음 공간이 분명하게 구분되는 것은 어음 변별력을 개선할 수 있고, 포먼트 주파수 보정을 통해 음색 보상, 성 별 구분 및 감정 인식 등에 도움을 줄수 있을 것으로 기대한다. 


\section{REFERENCES}

Borden, G. J., Harris, K. S., \& Raphael, L. J. (1994). Speech science primer. Baltimore, MD: Lippincott Williams \& Wilkins.

Borden, G. J., Harris, K. S., \& Raphael, L. J. (2000). Speech science primer: physiology, acoustics, and perception of speech (3rd ed., K. H. Kim et al., Trans.). Seoul: Hankookmunhwasa.

Cho, S. M. (2003). An acoustic study of Korean vowel system. Journal of Korean Language and Culture, 24, 427-441.

Choi, E. A., Park, H. S., \& Seong, C. J. (2010). The phonatory characteristics of voice in profoundly hearing-impaired children: with reference to F0, intensity, and their perturbations. Phonetics and Speech Sciences, 2(1), 135145.

Diehl, R. L., Lindblom, B., Hoemeke, K. A., \& Fahey, R. P. (1996). On explaining certain male-female differences in the phonetic realization of vowel categories. Journal of Phonetics, 24(2), 187-208.

Ferrand, C. T. (2007). Speech science: an integrated approach to theory and clinical practice (2nd ed., J. Han et al., Trans.). Seoul: Sigmapress.

Heo, S. (2012). Pure external auditory canal resonance. Journal of Speech \& Hearing Disorders, 21(3), 465-473.

Heo, S., \& Kang, H. (2017). Formant frequency changes of female voice /a/, /i/, /u/ in real ear. Phonetics and Speech Sciences, 9(1), 49-53.

Heo, S., \& Kim, D. (2018). Formant transition of nasal and liquid in the external auditory canal. Communication Sciences \& Disorders, 23(3), 775781.

Heo, S., \& Yoo, Y. (2002). Audiology (3rd ed.). Busan: Dong-A University Press.

Heo, S., Kang, H., \& Kim, D. (2018). Change of voice onset time on external ear. Journal of Rehabilitation Welfare Engineering \& Assistive Technology, 12(3), 199-204.

Heo, S., Kang, H. R., \& Ko, D. H. (2017). Influence of real ear resonance on male voice formant frequency. Communication Sciences \& Disorders, 22(3), 608-614.

Heo, S., Lee, J., Jeon, S., \& Kim, I. (2010). Resonance in the concha cavity is associated with the size of the pinna. Korean Journal of Communication \& Disorders, 15(1), 107-113.

Heo, S., Choi, A., \& Kang, M. (2006). Rehabilitative audiology. Seoul: Sigmapress.

Hong, K. H., Kim, H. K., Jung, K. S., Yoon, H. W., \& Kim, S. W. (1998). A study for the change of laryngeal position and vocal pitch with ageing pro- cess. The Journal of the Korean Society of Logopedics and Phoniatrics, 9(1), 79-85.

Hwang, Y. J. (2007). Normative nasalance scores and differences as a function of gender and residential area. Korean Journal of Communication \& Disorders, 12(3), 508-520.

Hwang, Y. J., Kim, H. K., Jeong, O. R., \& Lee, J. H. (2007). The average nasalance as a function of Korean and Chinese in vowels. Speech Sciences, 14(3), 139-146.

Kent, R. D., \& Read, C. (2002). The acoustic analysis of speech. San Diego, CA: Delmar/Cengage Learning.

Kim, J. H. (2016). Auditory late response analyses and acoustic features according to emotional status of /u/, /a/, /i/ (Master's thesis). Hallym University, Chuncheon, Korea.

Kim, Y. S., Kim, K. H., Kim, J. Y., \& Jang, J. S. (2013). A study on the formant comparison of Korean monophthongs according to age and gender: a survey on patients in oriental hospitals. Phonetics and Speech Sciences, 5(1), 73-80.

Koo, H. S. (2005). A study of the pronunciation of English vowels between male and female speakers. Speech Sciences, 12(2), 7-16.

Martin, F. N., \& Clark, J. G. (2016). Introduction to audiology (12th ed., S. Heo Trans.). Seoul: Pakhaksa.

Moon, S. (2007). A fundamental phonetic investigation of Korean monophthongs. MALSORI, 62, 1-17.

Oh, E. J. (2012). Effects of speaker gender on vowel space size and vowel changes in Korean. Journal of Studies in Language, 28(3), 531-553.

Seong, C. J. (2005). A formant analysis of the Korean monophthongs of the college students speaking Chungnam dialect. Language, (43), 189-213.

Shin, H., \& Yoon, S. (1987). A study on the formant analysis of Korean monophthongs and their resonance effect in vocal tract. The Journal of the Acoustical Society of Korea, 6(2), 30-37.

Simpson, A. P. (2002). Gender-specific articulatory-acoustic relations in vowel sequences. Journal of Phonetics, 30(3), 417-435.

Simpson, A. P. (2009). Phonetic differences between male and female speech. Language and Linguistics Compass, 3(2), 621-640.

Waaramaa, T., Laukkanen, A. M., Alku, P., \& Väyrynen, E. (2008). Monopitched expression of emotions in different vowels. Folia Phoniatrica et Logopaedica, 60(5), 249-255.

Whiteside, S. P. (2001). Sex-specific fundamental and formant frequency patterns in a cross-sectional study. The Journal of the Acoustical Society of America, 110(1), 464-478. 
Yang, B. G. (1998a). A study on vowel formant variation by vocal tract modification. Speech Sciences, 3, 83-92.

Yang, B. G. (1998b). Measurement of the vocal tract area of vowels By MRI and their synthesis by area variation. Speech Sciences, 4(1), 19-34.

Yang, B. G. (2008). Formant measurements of complex waves and vowels produced by students. Speech Sciences, 15(3), 39-51.

Yang, B. G. (2012). Pitch and formant trajectories of English vowels by American males with different speaking styles. Phonetics and Speech Sciences, 4(1), 21-28.
Yi, S. P. (2011). An analysis of formants extracted from emotional speech and acoustical implications for the emotion recognition system and speech recognition system. Phonetics and Speech Sciences, 3(1), 45-50.

Yoo, H., Kim, Y., Suh, Y., \& Kim, H. (2017). Voice transformation for HTS using correlation between fundamental frequency and vocal tract length. Phonetics and Speech Sciences, 9(1), 41-47.

Yoon, K., \& Kim, S. (2015). A comparative study on the male and female vowel formants of the Korean corpus of spontaneous speech. Phonetics and Speech Sciences, 7(2), 131-138. 


\section{국문초록}

\section{외이도에서 녹음한 남녀 음성의 음향학적 특성}

강희라 ${ }^{1}$ 허승덕 ${ }^{2}$

${ }^{1}$ 대구대학교대학원 재활과학과 언어치료전공, ${ }^{2}$ 대구대학교 재활과학대학 언어치료학과

배경 및 목적: 모음의 음향 자질은 변형된 성도를 지나면서 달라지며, 해부학적 구조와 발화 습관 등이 다른 남녀 차이에 따라서도 달 라진다. 소리는 외이를 통해 청각기관이 수용하며, 음향 특성은 성도와 마찬가지로 공명기인 외이도를 지나면서 더욱 달라질 수 있다.

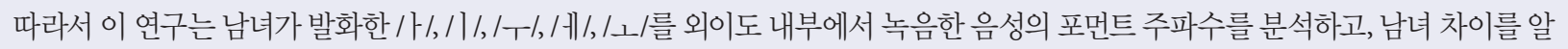
아보는 데 목적이 있다. 방법: 연구에는 10명의 여자(23세 \pm 3.77$)$ 와 8명의 남자(25세 \pm 3.68$)$ 가 화자로, 23세 남자 1명이 청자로 참여하 였다. 음성 녹음은 탐침관을 연결한 두 개의 콘덴서 마이크를 이용하였다. 남녀 음성은 마이크를 이개 상부(upper pinna)와 고막 $1 \mathrm{~cm}$ 가까이 외이도(external auditory canal) 내부로 삽입한 후 이수(lobule)에 각각 고정한 후 녹음하였다. 녹음한음성은 F1, F2, F3, F4를 각 각 구하여 기술통계하였다. 이개 상부와 외이도 내부 음성의 남녀 차이는 독립표본 $t$-test로 검증하였다. 결과: 이개 상부 음성의 남녀 차 이는 / / / 의 F1, F2, F3, F4 ( $p=.000)$, / / / 의 F1 ( $p=.000), \mathrm{F} 3$ ( $p=.012), \mathrm{F} 4$ ( $p=.000), / \mathrm{T} /$ 의 F1 ( $p=.000), / / 1 /$ 의 F1 ( $p=.000), \mathrm{F} 3(p=.000)$, $\mathrm{F} 4(p=.000)$, / ㄷ/의 F1 ( $p=.015), \mathrm{F} 4$ ( $p=.000)$ 에서 여자가 유의하게 높게 관찰되었다. 그러나/T/의 F2 ( $p=.039)$, / 시의 F2 ( $p=.004)$, $\mathrm{F} 3$ ( $p=.000)$ 은 유의하게 낮게 관찰되었다. 외이도 내부 음성의 남녀의 차이는 / / / 의 F1, F2, F3, F4 ( $p=.000)$, / / 의 F1 ( $p=.005), \mathrm{F} 2$ ( $p=.041), \mathrm{F} 3(p=.023), \mathrm{F} 4(p=.000), / / \| n /$ 의 $\mathrm{F} 2(p=.001), \mathrm{F} 3, \mathrm{~F} 4(p=.000)$ 가 여자가 유의하게 높게 관찰되었다. 논의 및 결론: 이개 상부 음성의 남녀 간차이는 F1, F2, 원순 및 평순모음의 F3, F4 등에 영향을 받아 여자의 모음 공간이 전체적으로 넓게 관찰되었다. 외이도 내 부음성의 남녀 간 차이는 여자의 저모음과 고모음, 전설 및 후설모음에서 F1과 F2의 차이가 커졌다. F3은 여자의 원순과 평순모음에서 높아졌고, $\mathrm{F} 4$ 는 여자의 저모음, 고모음과 전설 및 후설모음에서 모두 높게 관찰되었다. 외이도 내부 음성의 남녀 간 모음 공간은 분명하 게 구분되며, 특히 F3, F4의 모음 공간은 중복되지 않고 독립적으로 관찰되었다.

핵심어: 이개, 외이도, 포먼트 주파수, 성별 효과, 음성 분석

본 논문은 제 1 저자 강희라의 대구대학교 석사학위논문(2018)을 발췌한 것임.

기술자문을 준 김기련 박사, 김광년 이사께 감사를 표한다.

\section{참고문헌}

구희산(2005). 남.여 화자간의 영어모음 발음 연구. 음성과학, 12(2), 7-16.

김영수, 김근호, 김종열, 장준수(2013). 연령 및 성별에 따른 한국인 단모음 포먼트 비교에 관한 연구. 말소리와음성과학, 5(1), 73-80.

김준혁(2016) / / ㅇ/,/아/, /이/의 청성유발 후기 반응과 감정에 따른 음향학적 특성. 한림대학교 대학원 석사학위논문.

문승재(2007). 한국어 단모음의 음성학적 기반연구. 말소리, 62, 1-17.

성철재(2005). 충남지역 대학생들의 한국어 단모음 포먼트 분석. 언어학, (43), 189-213.

신현재, 윤석왕(1987). 한글 단모음의 포만트 분석과 성도내의 공명효과에 관한 연구. 한국음향학회지, 6(2), 30-37.

양병곤(1998a). 성도 변형에 따른 모음 포먼트의 변화 고찰. 음성과학, 3, 83-92.

양병곤(1998b). MRI에 의한 모음의 성도 단면적 측정 및 면적 변이에 따른 합성연구. 음성과학, 4(1), 19-34.

양병곤(2008). 복합음과 대학생이 발음한 모음 포먼트 측정. 음성과학, 15(3), 39-51.

양병곤(2012). 발화방식에 따른 미국인 남성 영어모음의 피치와포먼트 궤적. 말소리와음성과학, 4(1), 21-28.

오은진(2012). 모음 공간 크기 및 모음 변화에 대한 화자 성별의 효과: 한국어의 경우. 언어연구, 28(3), 531-553. 
유효근, 김영관, 서영주, 김회린(2017). 기본주파수와 성도길이의 상관관계를 이용한 HTS 음성합성기에서의 목소리 변환. 말소리와 음성과학, 9(1), 41-47.

윤규철, 김순옥(2015). 한국어 자연발화음성 코퍼스의 남녀 모음 포먼트 비교연구. 말소리와음성과학, 7(2), 131-138

이서배(2011). 독일어 감정음성에서 추출한 포먼트의 분석 및 감정인식 시스템과 음성인식 시스템에 대한 음향적 의미. 말소리와 음성과학, 3(1), 45-

50.

조성문(2003). 현대 국어의 모음 체계에 대한 음향음성학적인 연구. 한국언어문학, 24, 427-441.

최은아, 박한상, 성철재(2010). 심도 청각장애 아동의 발성 특성: 강도, 음도 및 그 변동률을 중심으로. 말소리와음성과학, 2(1), 134-145.

허승덕(2012). 순수 외이도 공명. 언어치료연구, 21(3), 465-473.

허승덕, 강희라(2017). 실이에서 여자음성///,/////T/의 포먼트 주파수 변화. 말소리와 음성과학, 9(1), 49-53.

허승덕, 강희라, 고도흥(2017). 외이 공명이 남자 음성 포먼트 주파수에 미치는 영향. Communication Sciences \& Disorders, 22(3), 608-614.

허승덕, 강희라, 김도윤(2018). 외이가 성대 진동 개시 시간에 미치는 변화. 재활복지공학회논문지, 12(3), 199-204.

허승덕, 김도윤(2018). 외이도에서 비음과 유음의 포먼트 전이. Communication Sciences \& Disorders, 23(3), 775-781.

허승덕, 유영상(2002). 청각학(제3판). 부산: 동아대학교 출판부.

허승덕, 이제현, 전성민, 김인아(2010). 이개 크기에 따른 이개강 공명. 언어청각장애연구, 15(1), 107-113.

허승덕, 최아현, 강명구(2006). 재활청각학: 인공와우, 보청기, 양이 청취. 서울: 시그마프레스.

홍기환, 김현기, 정경수, 윤희완, 김성완(1998). 연령에 따른 정상인의 후두 위치 및 기저주파수의 변화에 대한 연구. 대한후두음성언어학회, 9(1), 79-

85.

황영진(2007). 성별 및 지역 간 정상 성인의 비성도 연구. 언어청각장애연구, 12(3), 508-520.

황영진, 김하경, 정옥란, 이재홍(2007). 중국인과 한국인의 모음의 평균 비성도 연구. 음성과학, 14(3), 139-146.

Carole T. Ferrand (2007). (언어임상을 위한) 음성과학(제2판, 한지연 최양규 역). 서울: 시그마프레스.

Frederick N. Martin, John Greer Clark (2016). 청각학개론(제12판, 허승덕 역). 서울: 박학사.

Gloria J. Borden, Katherine S. Harris, Lawrence J. Raphael (2004). 음성과학: 조음, 음향, 청각음성학(제3판, 김기호, 양병곤, 고도흥, 구희산 역). 서 울: 한국문화사.

\section{ORCID}

강희라(https://orcid.org/0000-0002-4255-3899); 허승덕(https://orcid.org/0000-0001-9386-3865) 